\title{
Pulmonary artery rupture as a complication of Swan- Ganz catheter application. Diagnosis and endovascular treatment: a single centre's experience
}

\author{
Piotr N. Rudziński ${ }^{1}$, Jan Henzel ${ }^{1}$, Zofia Dzielińska ${ }^{1}$, Barbara M. Lubiszewska ${ }^{1}$, Ilona Michałowska², \\ Piotr Szymański ${ }^{3}$, Radosław Pracoń ${ }^{1}$, Tomasz Hryniewiecki ${ }^{3}$, Marcin Demkow ${ }^{1}$ \\ ${ }^{1}$ Department of Coronary and Structural Heart Diseases, Institute of Cardiology, Warsaw, Poland \\ 2Department of Radiology, Institute of Cardiology, Warsaw, Poland \\ ${ }^{3}$ Department of Acquired Cardiac Defects, Institute of Cardiology, Warsaw, Poland
}

Adv Interv Cardiol 2016; 12, 2 (44): 135-139

DOI: 10.5114/aic.2016.59364

\begin{abstract}
A bstract
Introduction: The placement of a Swan-Ganz catheter into the pulmonary artery may lead to a number of complications (2-17\%). In less than $0.2 \%$ of cases Swan-Ganz catheterization results in serious vascular damage - pulmonary artery rupture (PAR). This paper presents two distinct forms of iatrogenic PAR treated endovascularly using different vascular devices.

Aim: To evaluate the effectiveness of endovascular treatment and the application of different types of vascular devices in the management of pulmonary artery rupture caused by Swan-Ganz catheterization.

Material and methods: In this retrospective study we evaluated 2 patients in whom Swan-Ganz catheter application was used for perioperative monitoring and resulted in pulmonary artery rupture. This complication was treated endovascularly by means of interventional cardiology.

Results: We report the cases of 2 patients with a pulmonary artery pseudoaneurysm formed in the perioperative period. In case 1 , a single, 4-loop, $3 \mathrm{~mm}$ diameter coil was implanted. In case 2, a $5 \mathrm{~mm}$ Amplatzer Vascular Plug IV was applied. In both cases, the endovascular approach resulted in total occlusion of the feeding artery and reduced further extravasation of the blood.

Conclusions: Despite its extremely low incidence, iatrogenic PAR is a serious, life-threatening complication of Swan-Ganz catheterization that requires urgent attention. Among available methods of treatment, percutaneous embolization is a relatively quick, safe, accurate and highly effective alternative to traumatizing surgery.
\end{abstract}

Key words: pulmonary artery, pulmonary arteriovenous malformation, pulmonary pseudoaneurysm, Swan-Ganz catheter, transcatheter embolization, vascular plugs.

\section{Introduction}

The placement of a Swan-Ganz catheter into the pulmonary artery may lead to a number of complications (2-17\%) [1]. Those include arrhythmias, pneumothorax, heart block, lung infarction, perforation of the balloon, thrombosis, air embolism, knotting of the catheter, valvular damage, or infection. In less than $0.2 \%$ of cases SwanGanz catheterization results in serious vascular damage - pulmonary artery rupture (PAR) [2-5]. This paper presents two forms of iatrogenic PAR treated endovascularly using different vascular devices. We report the cases of 2 patients after surgical aortic valve replacement followed by formation of a pulmonary artery pseudoaneurysm in the perioperative period.

\begin{abstract}
Aim
The aim is to evaluate the effectiveness of endovascular treatment and the application of different types of vascular devices in the management of pulmonary artery rupture caused by Swan-Ganz catheterization.

Material and methods

In this retrospective study we evaluated 2 patients in whom Swan-Ganz catheter application had been used for perioperative monitoring and resulted in pulmonary artery rupture. This complication was treated endovascularly by means of interventional cardiology: metal coil embolization and vascular occluder application. Control
\end{abstract}



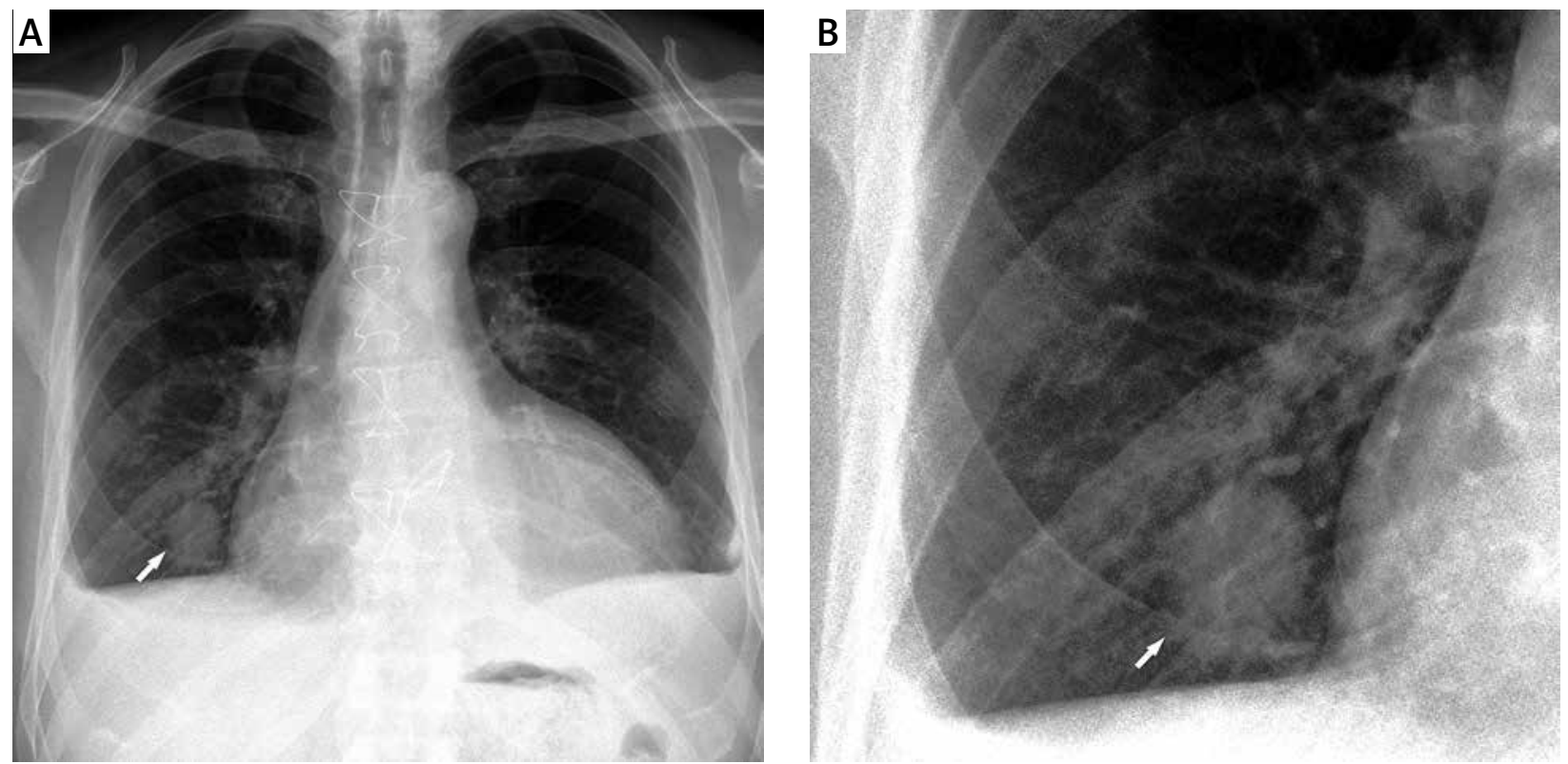

Figure 1. Case 1. Chest X-ray (A-P position). Circular shadow with a diameter of $26 \mathrm{~mm}$ is present in the place of previously described parenchymal changes (white arrows)

direct angiography and follow-up computed tomography were carried out in order to evaluate the effectiveness of the procedures.

\section{Results}

\section{Case 1}

A 55-year-old man was admitted for surgical treatment of severe bicuspid aortic stenosis. A mechanical aortic valve (SJM Regent Valve, diameter of $25 \mathrm{~mm}$ ) was successfully implanted. After surgery, the patient reported fever and haemoptysis. On the $7^{\text {th }}$ postoperative day, control chest X-ray showed atelectasis or inflammation

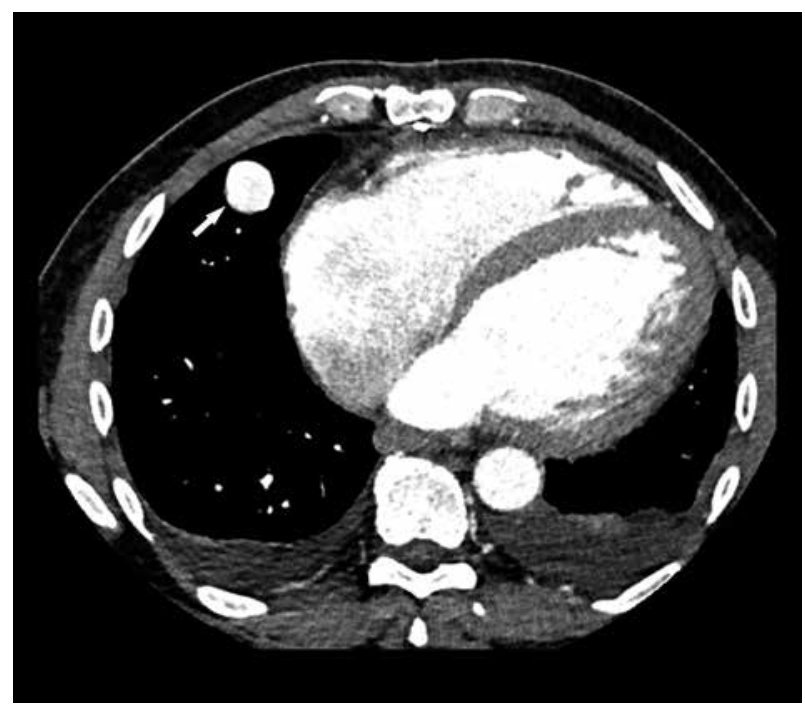

Figure 2. Case 1. Transverse section of chest computed tomography. Pulmonary artery pseudoaneurysm is present in the right lung (white arrow) of rear base segments of the right lung. Additionally, the presence of small quantities of fluid in both pleural cavities was revealed. One week later, control chest X-ray was performed again (Figure 1). In the place of previously described parenchymal densities, a circular shadow (26 mm diameter) was observed. Finally, computed tomography revealed a pseudoaneurysm of the right lower lobe supplied by a subsegmental pulmonary artery (Figure 2).

The patient was qualified for transcatheter embolization of the pseudoaneurysm. The procedure was performed 4 weeks after cardiac surgery using the femoral venous approach. The subsegmental pulmonary artery branch was cannulated with a 6-Fr Cournand catheter. Selective hand contrast injection indicated the ruptured artery actively bleeding into the pseudoaneurysmal sac. A single, 4-loop, $3 \mathrm{~mm}$ diameter coil (M Reye Flipper PDA Closure Detachable Coil, IMWCE-3-PDA-4, William Cook Europe) was implanted just above the artery rupture point and below the last bifurcation. The angiogram revealed complete closure of the feeding artery (Figure 3). Control chest X-ray revealed reduced size of the pseudoaneurysm and proper apposition of the vascular coil (Figure 4).

\section{Case 2}

A 68-year-old man was admitted due to severe aortic valve defect for further diagnosis and treatment. The patient had been qualified for cardiac surgery. Implantation of a biological aortic valve (Edwards Lifesciences $25 \mathrm{~mm}$ ) was performed with assistance of the SwanGanz catheter in perioperative monitoring. Control postoperative chest $\mathrm{X}$-rays revealed a large circular shadow in the lower lobe of the right lung imitating haematoma (Figure 5 A, PAP). Contrast computed tomography deter- 

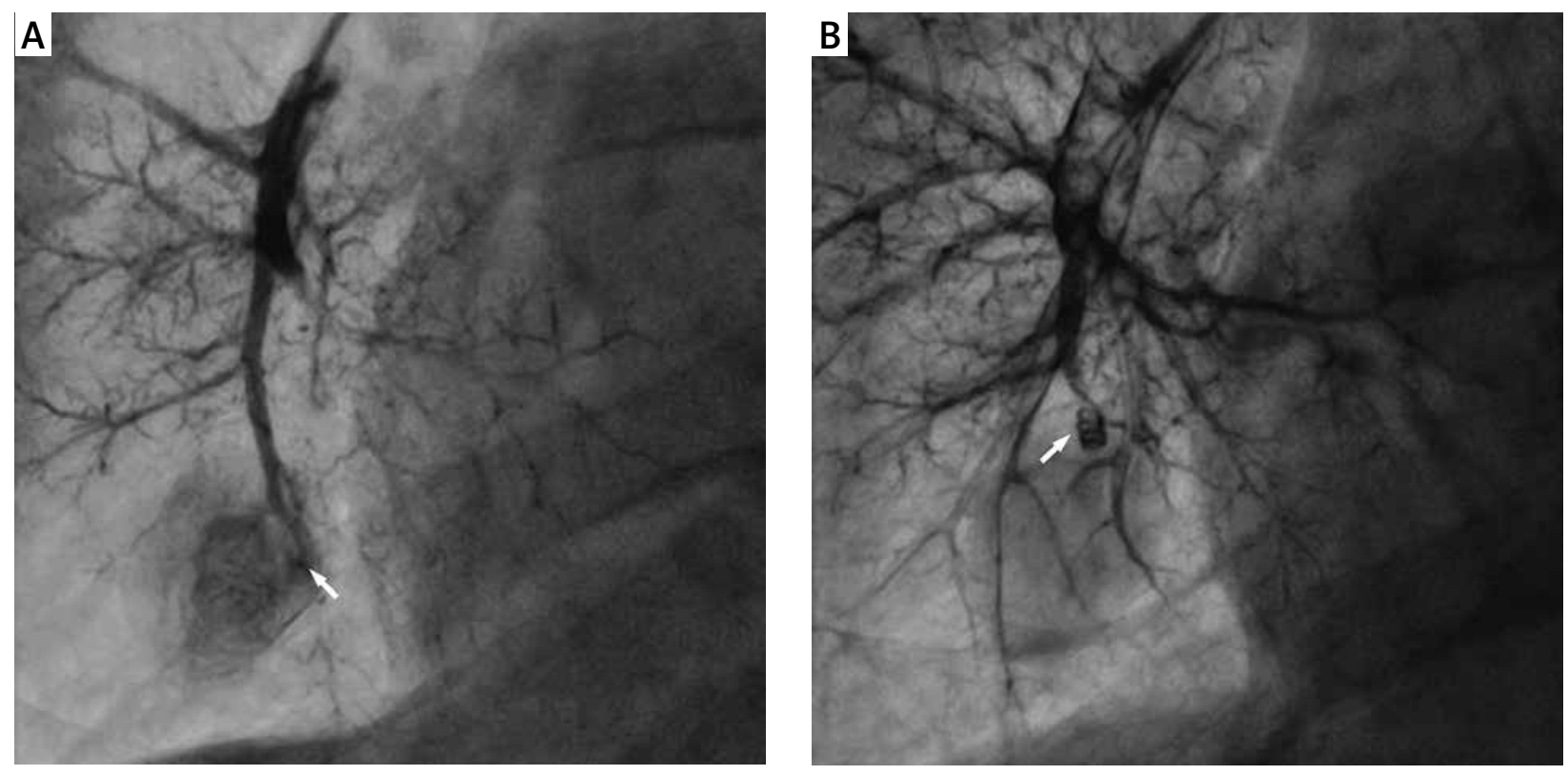

Figure 3. Case 1. Left angiogram: dye injection shows pulmonary artery rupture and arterial blood leakage (white arrow) with creation of the pseudoaneurysm. Right angiogram: the metal coil (white arrow) in the perforated artery occluding the feeding vessel
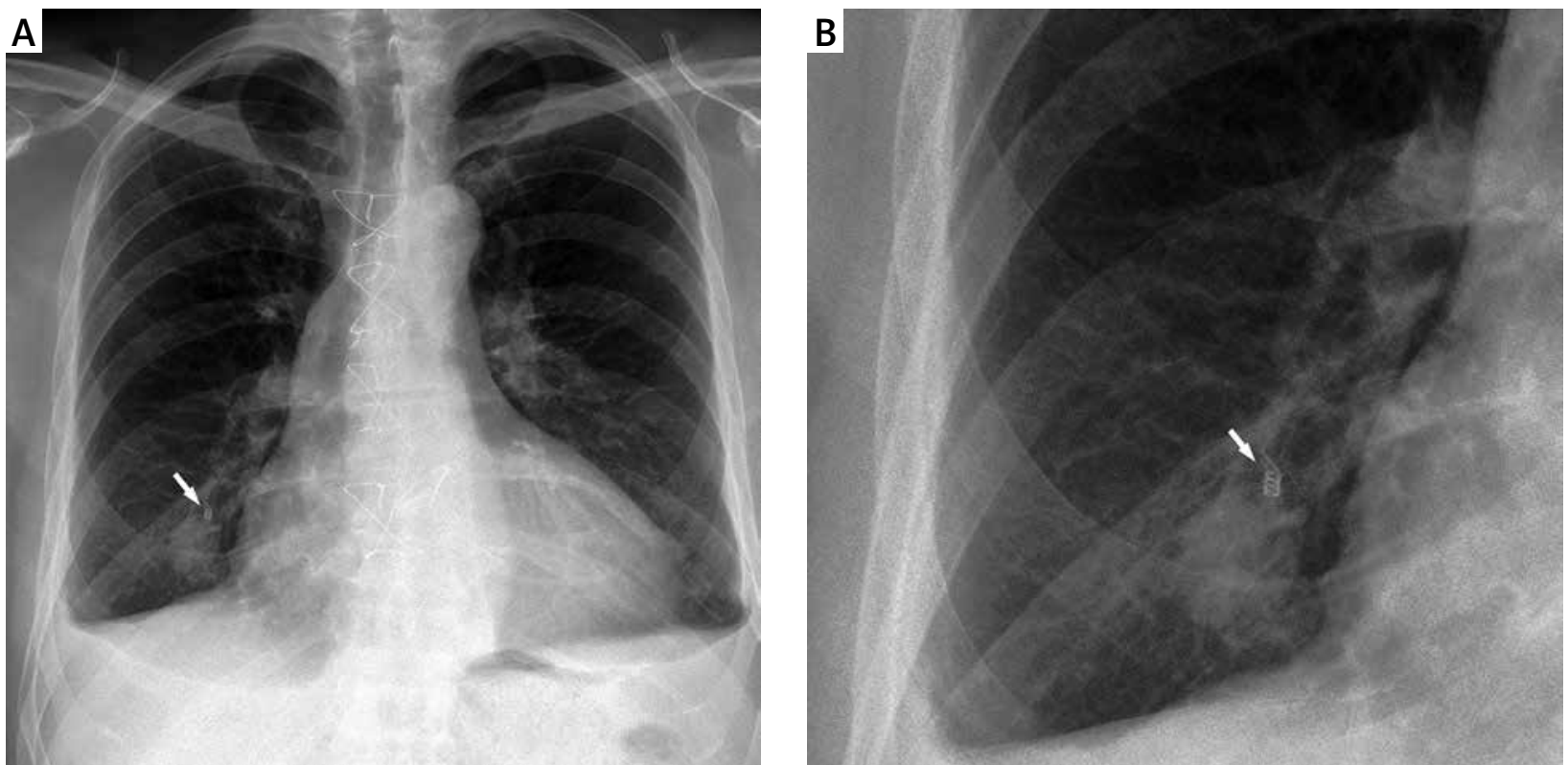

Figure 4. Case 1. Chest X-ray (A-P position). Allocation of the metal coil (white arrow) and reduction of the pseudoaneurysm

mined it as a pseudoaneurysm $(70 \times 50 \times 55 \mathrm{~mm})$ of the right inferior lobe supplied by a subsegmental pulmonary artery (Figure 5 B, 1). Pulmonary catheterisation was performed via femoral vein access. Selective contrast injection revealed a ruptured subsegmental artery branch actively bleeding into the pseudoaneurysm (Figure $5 \mathrm{~B}, 2$ ). A $5 \mathrm{~mm}$ Amplatzer Vascular Plug IV (AGA Medical Corporation, MN USA) was implanted just above the artery rupture point and below the last bifurcation. This resulted in complete closure of the feeding artery (Figure 5 B, 3).
The patient remained in a stable condition during the post-procedural period and after 1 week was discharged home without any evidence of pulmonary congestion. Two months later, control contrast computed tomography showed a significant reduction of the pseudoaneurysm $(50 \times 40 \times 40 \mathrm{~mm})$.

\section{Discussion}

Pulmonary artery rupture is a serious and dynamic complication [6-12], which can result in approximate- 


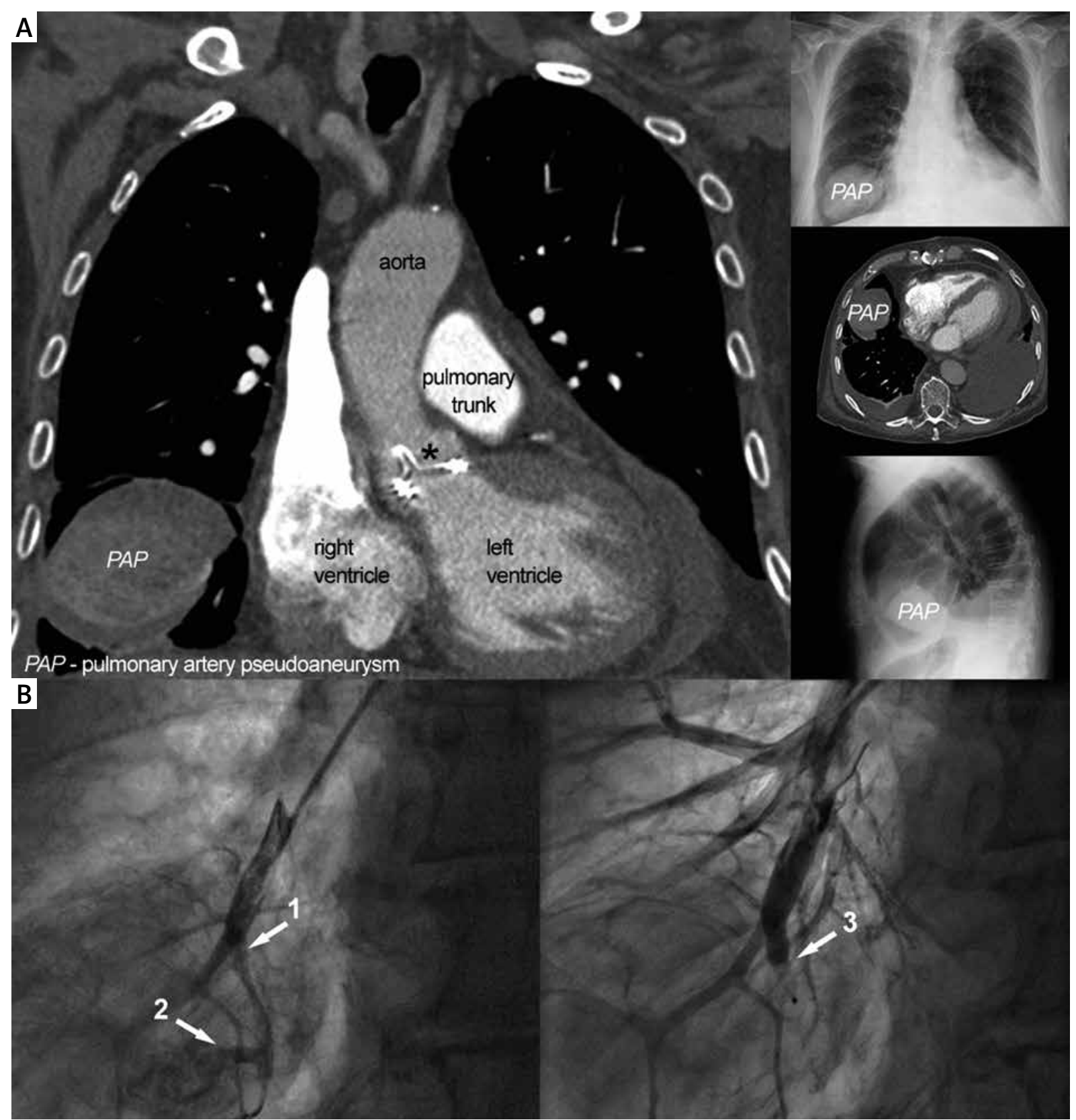

Figure 5. Case 2. A - Chest X-ray and computed tomography. Pulmonary artery pseudoaneurysm (PAP). B - Angiography helped to determine the feeding vessel which afterwards was successfully occluded with the Amplatzer Vascular Plug

ly $50 \%$ mortality $[10,13]$. The right lung is affected in $90 \%$ of cases [14]. The symptoms may vary from slight cough to massive haemorrhage. Extensive extravasation of blood to the lung parenchyma can promote creation of a pulmonary artery pseudoaneurysm. Some of those are formed instantly, while it takes months or years for others to develop imperceptibly. There have been some cases of asymptomatic PAR incidentally revealed in the autopsy [15]. Nonetheless, PAR is a life-threatening condition that should be recognized and treated immediately.

Mechanical complications of Swan-Ganz catheter application can be treated surgically [12] or endovascularly
$[3,16,17]$. Some authors propose conservative management and imaging follow-up for smaller vascular changes measuring less than $2.2 \mathrm{~cm}$ - limited haemorrhage and low risk of bleeding $[18,19]$. Extracorporeal membrane oxygenation (ECMO) may be a useful tool in supportive care. There is one case reported in which ECMO reduced the bleeding from the ruptured pulmonary artery. It was applied in order to improve blood oxygenation, to avoid severe hypoxemia and consequently to stabilize the patient [20]. Surgical treatment of PAR may involve reconstruction of the pulmonary artery, lobectomy or lung resection. Although it is much more traumatizing than endovascular 
treatment, in particular situations it is the only feasible method of therapy. In other cases, transcatheter closure of the injured artery is the first-choice procedure. Transcatheter detachable balloon technique [21, 22] or insertion of a specific coil (therapeutic gold standard) is commonly practiced by cardiac interventionists $[6,10,13]$. Another pattern consists of local thrombin injection using the distal port of the Swan-Ganz catheter. This method might be accompanied by balloon inflation - a temporary tamponade that can prevent the formation of PAP [23].

Implantable devices from the Amplatzer family of vascular plugs have been recently applied in the treatment of Swan-Ganz-catheter-induced PAR and its complications. The first application of an Amplatzer plug (AVPI) in the treatment of Swan-Ganz catheter-induced PAP was presented in 2010 [24]. Originally designed for venous or arterial embolization in peripheral vasculature, AVPs can be used as single device occluders delivered by particular catheters. Nitinol wire mesh structure and cylindrical shape ensure intravascular self-expandability, provide proper occlusion and guarantee more controlled and precise placement of the device. It can be recaptured, repositioned and redeployed when necessary.

\section{Conclusions}

Despite its extremely low incidence, iatrogenic PAR is a serious, life-threatening complication of Swan-Ganz catheterization that requires urgent attention. It is evident that re-operation strongly increases perioperative risk. Among available methods of treatment, percutaneous embolization is a relatively quick, safe, accurate and highly effective alternative to traumatizing surgery. Transcatheter treatment is still evolving by the constant improvement of various implantable devices (different in shape, size and material), which optimizes their usage and helps to adapt to particular clinical conditions.

\section{Conflict of interest}

The authors declare no conflict of interest.

\section{References}

1. Labrunie E, Levy C, Paugam C, et al. Pulmonary artery pseudoaneurysm caused by a Swan-Ganz catheter and treated by embolization. Ann Radiol (Paris) 1993; 36: 310-4.

2. Stancofski ED, Sardi A, Conaway GL. Successful outcome in Swan-Ganz catheter-induced rupture of pulmonary artery. Am Surg 1998; 64: 1062-5.

3. Bossert T, Gummert JF, Bittner HB, et al. Swan-Ganz catheter-induced severe complications in cardiac surgery: right ventricular perforation, knotting, and rupture of a pulmonary artery. I Card Surg 2006; 21: 292-5.

4. Troianos CA, Stypula RW. Transesophageal echocardiographic diagnosis of pulmonary artery catheter entrapment and coiling. Anesthesiology 1993; 79: 602-4.

5. Feng WC, Singh AK, Drew T. Swan-Ganz catheter-induced massive hemoptysis and pulmonary artery false aneurysm. Ann Thorac Surg 1990; 50: 644-6.
6. Poplausky MR, Rozenblit G, Rundback JH, et al. Swan-Ganz catheter-induced pulmonary artery pseudoaneurysm formation: three case reports and a review of the literature. Chest 2001; 120: 2105-11.

7. Bhatia P, Saied NN, Comunale ME. Management of an unusual complication during placement of a pulmonary artery catheter. Anesth Analg 2004; 99: 669-71.

8. Settergen G, Angdin M, Anderson RE, et al. Wedging the pulmonary artery catheter: changes in left atrial and pulmonary artery pressures and risk for performation. J Cardiothorac Vasc Anesth 2006; 20: 311-4.

9. Kierse $R$, Jensen $U$, Helmberger $H$, et al. Value of multislice $C T$ in the diagnosis of pulmonary artery pseudoaneurysm from SwanGanz catheter placement. J Vasc Interv Radiol 2004; 15: 1133-7.

10. Abreu AR, Campos MA, Krieger BP. Pulmonary artery rupture induced by a pulmonary artery catheter: a case report and review of the literature. J Intensive Care Med 2004; 19: 291-6.

11. Utsumi T, Kido T, Ohata T, et al. Swan-Ganz catheter-induced pseudoaneurysm of the pulmonary artery. Jpn J Thorac Cardiovasc Surg 2002; 50: 347-9.

12. Deren MM, Barash PG, Hammond GL, et al. Perforation of the pulmonary artery requiring pneumonectomy after the use of a flow-directed (Swan-Ganz) catheter. Thorax 1979; 34: 550-3.

13. Gottwalles Y, Wunschel-Joseph ME, Hanssen M. Coil embolization treatment in pulmonary artery branch rupture during Swan-Ganz catheterization. Cardiovasc Intervent Radiol 2000; 23: 477-9.

14. Kalra A, Heitner S, Topalian S. Iatrogenic pulmonary artery rupture during Swan-Ganz catheter placement - a novel therapeutic approach. Catheter Cardiovasc Interv 2013; 81: 57-9.

15. Bussières JS. Iatrogenic pulmonary artery rupture. Curr Opin Anaesthesiol 2007; 20: 48-52.

16. Finfer S, Delaney A. Pulmonary artery catheters. BMJ 2006; 333: 930-1.

17. Urschel JD, Myerowitz PD. Catheter-induced pulmonary artery rupture in the setting of cardiopulmonary bypass. Ann Thorac Surg 1993; 56: 585-9.

18. You CK, Whatley GS. Catheter-induced pulmonary artery pseudoaneurysm: a case of complete resolution without intervention. Can J Surg 1994; 37: 420-4.

19. Rouquier J, Arrivé L, Masini JP, et al. Spontaneous resolution of asymptomatic false aneurysm of the pulmonary artery induced by Swan-Ganz catheter. J Radiol 2001; 82: 1732-4.

20. Bianchini R, Melina G, Benedetto U, et al. Extracorporeal membrane oxygenation for Swan-Ganz induced intraoperative hemorrhage. Ann Thorac Surg 2007; 83: 2213-4.

21. Brahim JJ, Cheung D, Jessurun JA, et al. Rounded mass in the middle lobe after Swan-Ganz catheterization. Chest 2002; 121: 26163.

22. Cooper JP, Jackson J, Walker JM. False aneurysm of the pulmonary artery associated with cardiac catheterisation. Br Heart J 1993; 69: 188-90.

23. Dobies DR, Cohoon AL, Bates AA. Images in cardiovascular medicine. Repair of a perforated pulmonary artery due to a SwanGanz catheter using thrombin injection. Circulation 2009; 119: 521-2.

24. Burrel M, Real MI, Barrufet M, et al. Pulmonary artery pseudoaneurysm after Swan-Ganz catheter placement: embolization with vascular plugs. J Vasc Interv Radiol 2010; 21: 577-81. 